\title{
Psychopathic traits, victim distress and aggression in children
}

\author{
Yoast van Baardewijk, ${ }^{1,2}$ Hedy Stegge, ${ }^{2,3}$ Brad J. Bushman,, 4 \\ and Robert Vermeiren ${ }^{1,5}$ \\ ${ }^{1}$ Curium-Leiden University Medical Centre, Oegstgeest, The Netherlands; ${ }^{2}$ PI Research, Duivendrecht, \\ The Netherlands; ${ }^{3} \mathrm{VU}$ University, Amsterdam, The Netherlands; ${ }^{4}$ University of Michigan, Ann Arbor, USA; \\ ${ }^{5}$ VU Medical Centre, Amsterdam, The Netherlands
}

\begin{abstract}
Background: The relationship between psychopathic traits and aggression in children may be explained by their reduced sensitivity to signs of distress in others. Emotional cues such as fear and sadness function to make the perpetrator aware of the victim's distress and supposedly inhibit aggression. As children high in psychopathic traits show a reduced sensitivity to others' distress, these important interpersonal signals cannot perform their aggression inhibiting function. The present experiment tested the hypothesis that aggression in children with psychopathic traits can be attenuated by making distress cues more salient. Methods: $N=224$ participants from the community (53 \% boys, $M$ age $=10.81$ years, $S D=0.92)$ played a computer-based competitive reaction-time game against a simulated opponent by blasting him or her with loud noise through a headphone. The salience of the opponent's distress was increased for half of the participants (randomly selected) by a written message expressing his or her fear. Psychopathic traits were assessed using the Youth Psychopathic traits Inventory - Child Version (Van Baardewijk et al., 2008). Results: As expected, regression analysis showed that psychopathic traits were strongly related to aggression in the no distress condition but not in the distress condition. Thus, the relation between psychopathic traits and aggression depended upon the salience of the opponent's distress. Conclusions: It was concluded that children with psychopathic traits are indeed prone to act aggressively, but also that this aggression is dynamic and is dependent upon circumstances. Their aggression can be attenuated by a salient display of others' distress. These results suggest that empathy based treatment techniques may reduce aggression in children with psychopathic traits. Keywords: Psychopathy, aggression, victim distress, empathy, children, experiment.
\end{abstract}

Aggressive behavior is a serious problem in today's society. Longitudinal studies have shown that adolescent and adult aggressive and violent behaviors are rooted in childhood (Farrington, 1994; Loeber, 1982). Targeting childhood aggression will therefore likely reduce aggression at a later age (Tremblay, 1998). Thus, high priority should be given to understanding the mechanisms underlying childhood aggression, with a particular emphasis on subgroups of children with an increased risk for lifelong aggression problems, such as those with psychopathic traits. Previous research has shown psychopathic traits in children to be strongly associated with aggression in both clinical and community samples (Dadds, Fraser, Frost, \& Hawes, 2005; Frick, Cornell, Barry, Bodin, \& Dane, 2003; Frick, O’Brien, Wootton, \& McBurnett, 1994; Marsee, Silverthorn, \& Frick, 2005). Although highly valuable in several respects, past research has not provided insight into the mechanisms underlying the high incidence of aggression in children with psychopathic traits. Aggressive behavior is the result of an interaction of personality traits and circumstances (Bettencourt, Talley, Benjamin, \& Valentine, 2006). Although it is now well accepted that

Conflict of interest statement: No conflicts declared. psychopathic personality traits in children are related to high levels of aggression, the conditions under which aggressive acts are more, or less, likely to occur in this group have not yet been studied.

In this experimental study we propose one possible cause for the high incidence of aggression in children with psychopathic traits: their reduced sensitivity to cues of distress in others. We assessed the relationship between psychopathic traits and interpersonal aggression under two controlled conditions: one in which the salience of the victim's distress was intensified in order to increase the likelihood that this emotion cue is picked up by the participant (distress condition), and a control condition in which no information was given about the victim's distress (no distress condition).

The reduced sensitivity to signs of distress in others (i.e., fear and sadness) is a well-established empirical fact in psychopathic youth (Blair, Budhani, Colledge, \& Scott, 2005; Blair \& Coles, 2000; Blair, Colledge, Murray, \& Mitchell, 2001; Stevens, Charman, \& Blair, 2001). Although children with high psychopathic traits do not differ from other children in their ability to recognize happiness, anger or surprise, they have difficulty recognizing sadness and fear (Blair, 1999). This reduced sensitivity to distress may be the mechanism that explains the 
association between psychopathy and aggression. In interpersonal situations, the expression of sadness or fear provides perpetrators of aggressive acts instant feedback about the consequences of their actions. These emotional cues function to make the perpetrator aware of the victim's distress and supposedly inhibit aggressive acts (Blair, 1995). As children high in psychopathic traits show a reduced sensitivity to others' fear and sadness, they are more likely to miss these important interpersonal signals. As a consequence, these signals can not perform their inhibiting function, resulting in higher aggression levels.

An interesting question is whether aggression in children with psychopathic traits can be decreased by acting upon their reduced sensitivity to signs of distress. In one study (Blair et al., 2001), children were presented with a cinematic display of facial expressions that evolved through 20 stages from a neutral expression to an emotional expression. Children high in psychopathy needed significantly more stages, and thus a higher emotional intensity, to correctly identify fear and sadness than did children low in psychopathy. This finding suggests that enhancing the stimulus characteristics, i.e., making the victim's distress more intense or salient, increases the likelihood that the distress cue is picked up by children high in psychopathic traits. The distress cue can then perform its aggressioninhibiting task. The current study tests the hypothesis that confronting children high in psychopathic traits with more salient feelings of opponent's distress will decrease their level of aggression.

To test this hypothesis, we designed a procedure based on the Taylor Aggression Paradigm (Taylor, 1967). Children played a computer-based competitive reaction-time game against an unknown opponent under one of two different conditions. In the no distress condition, the participant was allowed to aggress against an ostensible opponent. In the distress condition, the participant was allowed to aggress as well but the salience of the opponent's distress was increased by a written message expressing his or her fear. In the no distress condition, we expected a positive relationship between psychopathy and aggression. Because we hypothesized aggression in children high in psychopathic traits to be inhibited by a salient expression of others' distress we expected no relationship between psychopathy and aggression in the distress condition.

\section{Method}

\section{Participants}

Participants were 228 children (53\% boys) from four primary schools in the Netherlands $(M$ age $=10.81$ years, $S D=0.92)$. Parental consent rate was $76.8 \%$. Most children (77\%) were Caucasian, 23\% had other (e.g., Surinam/Lesser Antilles, (North) African) or mixed ethical/cultural origins. Children received a small gift (e.g., markers) in exchange for their voluntary participation.

\section{Measure of psychopathy}

The 50-item Youth Psychopathic trait Inventory - Child Version (YPI-CV; Van Baardewijk et al., 2008) was used to measure psychopathy. It assesses the three core dimensions of psychopathy: Grandiose-Manipulative, Callous-Unemotional and Impulsive-Irresponsible. The instrument is adapted from the original Youth Psychopathic trait Inventory intended for adolescents (YPI; Andershed, Kerr, Stattin, \& Levander, 2002). The reliability and validity of the YPI has been confirmed in several studies in both community and adjudicated samples (Andershed, Hodgins, \& Tengstrom, 2007; Larsson, Andershed, \& Lichtenstein, 2006; Poythress, Dembo, Wareham, \& Greenbaum, 2006; Skeem \& Cauffman, 2003). The child version of the instrument was developed for use in 9- to 12-year-olds and was investigated with regard to psychometric properties by Van Baardewijk et al. (2008). Cronbach's alpha of the total score was .92 and test-retest reliability coefficients over a period of 2 and 6 months were .77 and .76, respectively. Scores showed expected relations to theoretically relevant constructs such as teacher-assessed psychopathy, self-reported, peer-reported and situational empathy, self-reported narcissism and peerand teacher-reported attention-deficit/hyperactivity/ impulsivity problems. Items are scored using scales ranging from 1 (does not apply at all) to 4 (applies very well). Sample items include 'Feeling bad when you have done something wrong is a waste of time.', 'It's fun to make up stories and try to get people to believe them.', and 'I find rules to be nothing but a nuisance.' Participants completed the YPI-CV a few weeks before the experiment.

\section{Procedure}

Participants were told that they were to play a computer game that would help researchers understand how to help children with social problems. They were told that they could leave anytime and still would receive a gift. No children refused cooperation or expressed willingness to leave prematurely. After written participant assent was obtained, they completed an internet reaction time game called FastKid! (Thomaes, Bushman, Stegge \& Olthof, 2008) with an opponent of the same gender and grade from a different school. In reality, no opponent existed and the computer controlled all events. Fastkid! is based on the Taylor Aggression Paradigm (Taylor, 1967), which has been well validated in adults (e.g., Giancola \& Zeichner, 1995). Recent studies have shown that this paradigm is also a valid measure of aggression in adolescents (Konijn, Nije, Bijvank, \& Bushman, 2007) and in children (Murphy, Pelham, \& Lang, 1992; Thomaes et al., 2008; Waschbusch, Pelham, Jennings, Greiner, Tarter, \& Moss, 2002).

Participants were told that FastKid! consisted of two 5-trial rounds, and each round had a bonus. The 
first-round bonus was the ability to send a written message to the opponent at the end of the first round. The second-round bonus was the ability to blast the opponent with noise through headphones after winning a trial during the second round. Through a rigged lottery, the opponent owned the bonus in the first round, whereas the participant owned the bonus in the second round. Participants were given samples of white noise (sounds like radio static) they could set for their opponent. The noise levels ranged from 55 decibels (dB) (level 1) to $100 \mathrm{~dB}$ (level 10), in $5 \mathrm{~dB}$ increments. The maximum noise level, $100 \mathrm{~dB}$, is about the same intensity as a smoke or fire alarm. A non-aggressive nonoise setting (level 0) was also included. They were told that noise levels 7 and higher would hurt their opponent's ears.

By a flip of the coin each participant was assigned to either the distress or no distress condition. All participants lost the first 5-trial round. After the first round, participants in the distress condition received a message from the opponent that expressed feelings of distress: 'The first round was okay, but those noise blasts seem pretty loud. I'm pretty worried about them.' Participants in the no distress condition also received a message from the opponent, but it did not express any distress: 'The first round was okay. Are we halfway done already?? That's pretty quick.' After the message was received and read, the second 5-trial round began. In this round, participants owned the 'noise bonus,' so they could blast their opponent with noise levels of choice after winning a trial. Prior to each of the five trials of round 2, participants set the noise level their opponent would receive if the opponent lost. After each trial, participants were informed whether they had won (i.e., trial 1, 2, 4, and 5) or lost (i.e., trial 3) that trial. To obtain an aggression measure unconfounded by the effect of losing trial 3, the average level of noise set for the opponent across the first 3 trials was used to measure aggression. The alpha coefficient for the aggression measure was .84. Finally, participants were thoroughly debriefed to remove lingering effects of the manipulations.

Occasionally, aggression research is faulted for using laboratory procedures that are 'artificial' or 'unrepresentative' of 'real-life' aggression. The validity of laboratory aggression procedures (including our noise blast procedure) has been established by results from two meta-analyses. One meta-analysis showed impressive levels of convergence across a wide range of laboratory aggression measures (Carlson, Marcus-Newhall, \& Miller, 1989). The other meta-analysis showed that 'real' and laboratory measures of aggression are influenced in similar ways by situational variables (e.g., alcohol, provocation) and by individual difference variables (e.g., trait aggressiveness, gender) (Anderson \& Bushman, 1997).

\section{Results}

\section{Preliminary analyses}

Equivalence of experimental conditions. As can be seen in Table 1, psychopathy scores, age, and gender did not differ between the children assigned to distress and neutral conditions, indicating that the random assignment to conditions was effective.

Sex and age differences. As expected, boys were significantly more aggressive than girls, $F(1,226)=$ $34.71, p<.0001, d=.79$. However, no interactions involving gender were found. Data for boys and girls were therefore combined for subsequent analyses.

No main effects or interaction effects involving age were found. Data for different ages were also combined for subsequent analyses.

\section{Primary analyses}

The data were analyzed using hierarchical multiple regression analyses, with aggression (mean of first three noise blasts) as the dependent variable. Predictor variables were self-reported psychopathic traits (YPI; continuous), distress condition (discrete; no distress $=0$, distress $=1$ ), and their interaction (psychopathy $\times$ distress). Self-reported psychopathic traits were centered to reduce multicollinearity (Aiken \& West, 1991). The main effect of selfreported psychopathic traits and condition were entered in Step 1, and the interaction term was entered in Step 2.

The regression analyses yielded a significant main effect for psychopathy, $t(224)=4.61, p<.0001, b=$ $.59, \beta=.24$. The higher the level of psychopathy, the higher the level of aggression. No significant main effect was found for distress condition, $t(224)=.25$, $p=.80, b=.016, \beta=-.074$. Most important, there was a significant interaction between psychopathic traits and condition, $t(224)=-2.81, \quad p<.005$, $b=-.89, \beta=-.26$ (see Figure 1). As expected, psychopathic traits were positively related to aggression in the no distress condition but not in the distress condition, $t(102)=4.84, p<.0001, b=2.78, \beta=.43$ and $t(122)=.78, p=.44, b=.46, \beta=.071$, respectively. The model $\mathrm{R}^{2}$ was .058 in Step 1, and .090 in Step 2, a significant $R^{2}$ change, $F(1,224)=7.85$, $p=.006)$. Maximum Cook's distances were .12 and .04 for the distress and control conditions, respectively. These values are well below the value that is

Table 1 Psychopathic traits (mean score on YPI-CV), gender and age for children in the distress and no distress conditions

\begin{tabular}{|c|c|c|c|c|c|c|}
\hline & \multirow[b]{2}{*}{ Range } & \multicolumn{2}{|c|}{$\begin{array}{c}\text { Distress }(n=124) \\
54 \% \text { boys }\end{array}$} & \multicolumn{2}{|c|}{$\begin{array}{c}\text { No distress } \\
(n=104) 52 \% \\
\text { boys }\end{array}$} & \multirow[b]{2}{*}{$t$-test } \\
\hline & & Mean & $S D$ & Mean & $S D$ & \\
\hline Psychopathy score & $1.02-2.42$ & 1.63 & .36 & 1.60 & .37 & $t(226)=.52, p=.60$ \\
\hline Age & $9.13-12.76$ & 10.87 & .93 & 10.74 & .91 & $t(226)=-1.13 ; p=.26$ \\
\hline
\end{tabular}




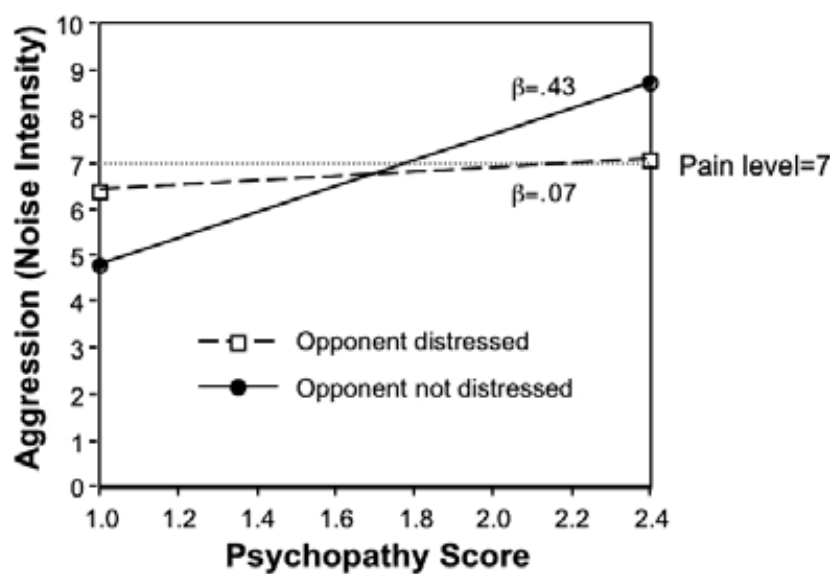

Figure 1 Relation between psychopathic traits and aggression for participants in either the no distress control condition or distress condition. The lines in the figure are regression lines. $\beta=$ standardized regression coefficient

considered cause for concern $(>1$; Cook \& Weisberg, 1982), indicating that our regression models were not influenced by a small number of extreme cases.

When focusing on the extreme groups, similar results were found. Two groups were created: high psychopathy (scoring $>1 S D$ above the mean, $n=33$ ) and low psychopathy (scoring $<1 S D$ below the mean, $n=31$ ). As expected, there was a significant main effect for psychopathy group. Children in the high psychopathy group were more aggressive than children in the low psychopathy group $(F(1,63)=$ $12.85, p=.001)$. No effect for condition was found $(F(1,63)=.25, p=.88)$ but the interaction effect was significant $(F(1,63)=8.14, p=.006)$. Simple effect analyses revealed that this interaction could chiefly be attributed to the high psychopathy group. In this group, children were significantly less aggressive in the distress condition (noise level $M=6.91$, $S D=2.95$ ) than in the no distress condition (noise level $M=8.72, S D=1.48)(t(29.59)=2.31, p=.029)$. By contrast, in the low psychopathy group, the difference in aggression between conditions just failed to reach significance $(t(29.00)=-2.01$, $p=.053)$. Children in the low psychopathy group were thus not significantly more aggressive in the distress condition (noise level $M=6.48, S D=2.30$ ) than in the no distress condition (noise level $M=4.87, S D=2.15)$.

\section{Discussion}

In the current study, we hypothesized that aggression in children with psychopathic traits could be reduced if these children were made aware of the distress of others. Normally children high in psychopathic traits show low sensitivity to others' distress. To test this hypothesis we experimentally assessed the relationship between psychopathic traits and aggression in children under two controlled conditions, one in which no information was given about the feelings of the opponent and one in which the opponent's distress was made explicit. As expected, the relation between psychopathic traits and aggression differed in these two conditions. In the control condition, in which the opponent's feelings were not salient, children with higher psychopathic traits acted more aggressively against their victim, with children with the highest levels of psychopathic traits in our sample blasting at a volume that exceeded the pain level of the opponent. In the experimental condition, when the distress of the opponent was made salient, there was no relationship between psychopathy and aggression. Children high in psychopathic traits were lower in aggression and no different from their counterparts with low psychopathic traits.

These findings confirm the results from earlier studies that have found a relationship between psychopathic traits and aggression in children. Our findings also expand on the existing literature. Earlier studies have regarded the relationship between psychopathic traits and aggression in children as static. Our study, using a behavioral measure of physical aggression rather than more commonly used pencil-and-paper measures, shows that this relationship is dependent upon the salience of the opponent's distress. We can thus conclude that children with psychopathic traits are indeed prone to act aggressively, but also that this aggression is dynamic and is dependent upon circumstances. In fact, aggression can be attenuated in children with psychopathic tendencies if they are stimulated to focus on their victim's pain and discomfort.

Our findings also have practical implications. The current study showed that when others' distress was emphasized, aggression in children high in psychopathic traits was inhibited. This suggests that helping children with high psychopathic traits to be more alert to the emotional signals of others could be a potential intervention strategy for reducing their aggression.

As we know that, to date, treatment of psychopathy in adulthood has not had favorable results (Harris \& Rice, 2006), it is essential that this type of interventions take place early in the developmental trajectory when interventions are more effective. However, although research is still scarce, several studies have shown children with psychopathic traits to show a reduced response to interventions. One study (Hawes \& Dadds, 2005) showed that young boys (age 4-9) with early onset conduct problems and additional psychopathic traits were less responsive to a parenting intervention program than those with early onset conduct problems only. At follow-up, 6 months later, children with the most stable high psychopathic traits showed the poorest outcome (Hawes \& Dadds, 2007). Another study (Waschbusch, Carrey, Willoughby, King, \& Andrade, 
2007) showed that children (age 7-12) with attention-deficit/hyperactivity disorder (ADHD) and conduct problems with additional psychopathic traits were less likely to be normalized by group wise behavioral therapy treatment with additional stimulant medication than were children with ADHD and conduct problems only. These findings suggest that treatment programs need to be developed, or existing ones need to be modified, to specifically fit the needs of children with psychopathic traits. Our findings suggest that interventions that incorporate the induction of awareness of another's emotional state could be effective in this group, at least for reducing aggression.

Parenting techniques that do just that have been proposed. An example is an empathy induction parenting technique aimed at stimulating prosocial and moral behavior in children (see Hoffman, 2000). It is comparable to our experimental manipulation as it involves the parent focusing the attention of the transgressing child on the feelings of the victim by heightening the salience of the victim's distress and emphasizing the part the transgressor played in causing these feelings. Similarly, parents may be trained to provide their children with opportunities (e.g., pretend play, role play or emotion stories) for vicariously experiencing empathy (Izard, Fine, Mostow, Trentacosta, \& Campbell, 2002). Indeed, this is the type of intervention that was recently proposed by Frick and Dickens (2006) as specifically fitting the needs of children with psychopathic traits, as opposed to children with conduct disorder (CD) or oppositional-defiant disorder (ODD) problems who would better be helped with interventions based on parental supervision and discipline or anger-control.

First, however, further research is needed on the mechanism of others' distress and aggressive acts in children with psychopathic traits. In our experiment, the proposed mechanism, that children with psychopathic traits commit aggressive acts because they show reduced sensitivity to others' distress, was only indirectly examined. Similarly, the exact mechanism through which the increased salience of the opponent's distress brought about the inhibition in aggression seen in the distress condition is not clear. Distress in a victim can be picked up and processed automatically (e.g., through mimicry, the automatic sharing of the emotion), but if the victim expresses his or her distress verbally or in writing, observers can be empathically aroused through mediated association or role taking (Hoffman, 2000). Although cognitive and affective elements of empathy are often regarded as separate, this may represent a false dichotomy. Cognitive and affective empathic processes influence each other (Duan \& Hill, 1996; Hoffman, 2000; Miller \& Eisenberg, 1988). The final empathic response to a sign of distress in everyday natural behavior (be it, for example, comforting, walking away or inhibiting aggression) is therefore a product of both automated affective responding and cognition control. As the opponent's distress cue in our experiment was delivered in writing and did not require an immediate response, automated affective responding in combination with cognitive perspective taking could have played a role in the relation between distress and empathic responding (i.e., the inhibition of aggression). In order to examine the exact mechanism and the relative weights of cognitive versus affective empathy mediating between psychopathic traits and aggression, we would have been required to measure these constructs during the experiment. We chose not to do this because we feared this would negatively influence the believability of our procedure and make our participants suspicious. Future research should investigate the mediating role of cognitive and affective forms of reduced sensitivity to others' feelings in the relation between psychopathic traits and aggressive behaviors.

An unexpected, but interesting, finding in our study was that children with the lowest psychopathic traits showed increased aggression in the distress condition compared to the no distress condition, although this finding failed to reach significance. It should also be noted that this increase did not result in a noise blast volume that exceeded the pain level. Because this finding was not hypothesized and did not reach significance, explanations may be speculative. It is known that another's suffering or distress does not always generate feelings of empathy and prosocial behavior. Research shows that some groups of victims of bullying, for example, are characterized by submissive behaviors (Griffin $\&$ Gross, 2004). It may be that because the children with low psychopathic traits included in our experiment were already attuned to the welfare of the victim without it having to have been made salient, they actually may have considered the explicit expression of fear to be overly submissive, resulting in an aggressive reaction. Similarly, research on display rules has revealed that children, especially in middle childhood, are highly concerned with expressing their 'coolness' and emotional control towards peers (Parker \& Gottman, 1989; Underwood, Shockner, \& Hurley, 2001), much more so than towards parents (Zeman \& Garber, 1996; Zeman \& Shipman, 1997). The expressing of emotions, especially feelings of distress and anger, is expected by children to result in negative interpersonal consequences from peers (Zeman \& Garber, 1996; Zeman \& Shipman, 1997). It may be that, in our experiment, participants with low psychopathic traits 'punished' their opponent for being too explicit in their expression of fear. Children with high psychopathic traits, by contrast, may not have regarded this expression as too explicit because more subtle distress clues do not reach them. Our results thus show that the effect of heightening the salience of distress cues on aggression is quite subtle and dependent on the level of psychopathic traits and possibly on the conveyer of the message as well. 
Future studies could look into the relative importance of either of these factors.

Finally, it is advised that our experiment is replicated in a high-risk sample. Research investigating psychopathic traits in youth in community samples has generally produced results quite similar to clinic-referred or high-risk samples (e.g. Andershed et al., 2002; Dadds et al., 2005; Marsee et al., 2005; Van Baardewijk et al., 2008) and psychopathy in youth, like in adults, is now considered to be a continuum rather than a taxon (Murrie et al., 2007). Most studies investigating reduced sensitivity in children with psychopathic traits have, however, focused on clinic-referred samples (Blair, 1997; Blair et al., 2005, 2001; Stevens et al., 2001). It may thus be that children with extreme psychopathy scores, or with a conduct problems diagnosis with additional psychopathic traits, react differently to our distress manipulation.

\section{Conclusion}

Aggression is a serious problem in today's society, and probably in tomorrow's society as well. As the violent offenders of tomorrow are likely children that act aggressively today, it is important that we find means to reliably identify those children at risk, unravel the mechanisms of their aggression, and find ways to reduce it. Our finding that aggression in children with psychopathic traits is dynamically dependent on circumstances may attenuate the generally pessimistic view of scientists and therapists on the malleability of psychopathy and their behavioral consequences. The finding that aggression in children with high psychopathic traits can, at least temporarily, be inhibited by intensifying the display of the victim's distress may provide a small but essential piece of the puzzle of future intervention strategies aimed at reducing the risk for a deviant and societally harmful development in this important group.

\section{Author note}

Data analysis: the first author had full access to all the data in the study, and takes responsibility for the integrity of the data and the accuracy of the data analysis.

\section{Acknowledgements}

The authors would like to thank all children and schools that participated in this study and Carol Bos for programming the task.

\section{Correspondence to}

Yoast van Baardewijk, Curium LUMC, Endegeesterstraatweg 27, 2342 AK Oegstgeest, The Netherlands; Tel: +31 (0)71 5159600; Fax: +31 (0)71 5171414; Email: y.van_baardewijk@curium.nl; yoast_vb@dds.nl

\section{What we know:}

- Children with psychopathic traits show high levels of aggression.

- This may be explained by their reduced sensitivity to signs of distress in others.

\section{What is new:}

- We have shown that their aggression can be attenuated by increasing the salience of others' distress.

\section{What is clinically relevant:}

- Our finding may attenuate the generally pessimistic view of scientists and therapists on the malleability of psychopathy and their behavioral consequences. Our results suggest that empathy based treatment techniques may reduce aggression in children with psychopathic traits.

\section{References}

Aiken, L.S., \& West, S.G. (1991). Multiple regression: Testing and interpreting interactions. Newbury Park: Sage.

Andershed, H., Hodgins, S., \& Tengstrom, A. (2007). Convergent validity of the Youth Psychopathic Traits Inventory (YPI): Association with the Psychopathy
Checklist: Youth Version (PCL:YV). Assessment, 14, 144-154.

Andershed, H., Kerr, M., Stattin, H., \& Levander, S. (2002). Psychopathic traits in non-referred youths: Initial test of a new assessment tool. In E.S. Blaauw (ed.), Psychopaths: Current international perspectives (pp. 131-158). The Hague: Elsevier. 
Anderson, C.A., \& Bushman, B.J. (1997). External validity of 'trivial' experiments: The case of laboratory aggression. Review of General Psychology, 1, 19-41.

Bettencourt, B.A., Talley, A.E., Benjamin, A.J., \& Valentine, J. (2006). Personality and aggressive behavior under neutral and provoking conditions: A metaanalytic review. Psychological Bulletin, 132, 751-777.

Blair, R.J.R. (1995). A cognitive developmental approach to morality: Investigating the psychopath. Cognition, 57, 1.

Blair, R.J.R. (1997). Moral reasoning in the child with psychopathic tendencies. Personality and Individual Differences, 22, 731-739.

Blair, R.J.R. (1999). Responsiveness to distress cues in the child with psychopathic tendencies. Personality and Individual Differences, 27, 135.

Blair, R.J.R., Budhani, S., Colledge, E., \& Scott, S. (2005). Deafness to fear in boys with psychopathic tendencies. Journal of Child Psychology and Psychiatry, 46, 327-336.

Blair, R.J.R., \& Coles, M. (2000). Expression recognition and behavioral problems in early adolescence. Cognitive Development, 15, 421-434.

Blair, R.J.R., Colledge, E., Murray, L., \& Mitchell, R.A. (2001). A selective impairment in the processing of sad and fearful expressions in children with psychopathic tendencies. Journal of Abnormal Child Psychology, 29, 491.

Carlson, M., Marcus-Newhall, A., \& Miller, N. (1989). Evidence for a general construct of aggression. Personality and Social Psychology Bulletin, 15, 377-389.

Cook, R.D., \& Weisberg, S. (1982). Residuals and influence in regression. New York: Chapman \& Hall.

Dadds, M.R., Fraser, J., Frost, A., \& Hawes, D.J. (2005). Disentangling the underlying dimensions of psychopathy and conduct problems in childhood: A community study. Journal of Consulting and Clinical Psychology, 73, 400-410.

Duan, C., \& Hill, C.E. (1996). The current state of empathy research. Journal of Counseling Psychology, 43, 261-274.

Farrington, D.P. (1994). Human development and criminal careers. In M. Maguire, R. Morgan, R. Reiner (Eds), The Oxford handbook of criminology. Oxford: Oxford University Press.

Frick, P.J., Cornell, A.H., Barry, C.T., Bodin, S.D., \& Dane, H.E. (2003). Callous-unemotional traits and conduct problems in the prediction of conduct problem severity, aggression, and self-report of delinquency. Journal of Abnormal Child Psychology, 31, 457.

Frick, P.J., \& Dickens, C.. (2006). Current perspectives on conduct disorder. Current Psychiatry Reports, 8, 1.

Frick, P.J., O’Brien, B.S., Wootton, J.M., \& McBurnett, K. (1994). Psychopathy and conduct problems in children. Journal of Abnormal Psychology, 103, 700707.

Giancola, P.R., \& Zeichner, A. (1995). Construct validity of a competitive reaction-time aggression paradigm. Aggressive Behavior, 21, 199-204

Griffin, R.S., \& Gross, A.M. (2004). Childhood bullying: Current empirical findings and future directions for research. Aggression and Violent Behavior, 9, 379400.
Harris, G.T., \& Rice, M.E. (2006). Treatment of psychopathy: A review of the empirical findings. In C.J. Patrick (Ed.), Handbook of psychopathy (pp. 555572). New York: Guilford Press.

Hawes, D.J., \& Dadds, M.R. (2005). The treatment of conduct problems in children with callous-unemotional traits. Journal of Consulting and Clinical Psychology, 73, 737-741.

Hawes, D.J., \& Dadds, M.R. (2007). Stability and malleability of callous-unemotional traits during treatment for childhood conduct problems. Journal of Clinical Child and Adolescent Psychology, 35, 347355.

Hoffman, M.L. (2000). Empathy and moral development: Implications for caring and justice. New York: Cambridge University Press.

Izard, C.E., Fine, S.E., Mostow, A.J., Trentacosta, C.J., \& Campbell, J. (2002). Emotion processes in normal and abnormal development and preventative intervention. Development and Psychopathology, 14, 761767.

Konijn, E.A., Nije Bijvank, M., \& Bushman, B.J. (2007). I wish I were a warrior: The role of wishful identification in effects of violent video games on aggression in adolescent boys. Developmental Psychology, 43, 1038-10044.

Larsson, H., Andershed, H., \& Lichtenstein, P. (2006). A genetic factor explains most of the variation in the psychopathic personality. Journal of Abnormal Psychology, 115, 221-230.

Loeber, R. (1982). The stability of antisocial and delinquent child behavior: A review. Child Development, 53, 1431-1446.

Marsee, M.A., Silverthorn, P., \& Frick, P.J. (2005). The association of psychopathic traits with aggression and delinquency in non-referred boys and girls. Behavioral Sciences and the Law, 23, 803-817.

Miller, P.A., \& Eisenberg, N. (1988). The relation of empathy to aggressive and externalizing/antisocial behavior. Psychological Bulletin, 103, 324-344.

Murphy, D.A., Pelham, W.E., \& Lang, A.R. (1992). Aggression in boys with attention deficit-hyperactivity disorder: Methylphenidate effects on naturalistically observed aggression, response to provocation, and social information processing. Journal of Abnormal Child Psychology, 20, 451-466.

Murrie, D.C., Marcus, D.K., Douglas, K.S., Lee, Z., Salekin, R.T., \& Vincent, G. (2007). Youth with psychopathy features are not a discrete class: A taxometric analysis. Journal of Child Psychology and Psychiatry, 48, 714-723.

Parker, J.G., \& Gottman, J. (1989). Social and emotional development in a relational context: Friendship interaction from early childhood to adolescence. In T.J. Bernt, \& G.W. Ladd (Eds.), Peer relationships in child development (pp. 95-132). New York: Wiley.

Poythress, N.G., Dembo, R., Wareham, J., \& Greenbaum, P. (2006). Construct validity of the Youth Psychopathic traits Inventory (YPI) and the Antisocial Process Screening Device (APSD) with justice involved adolescents. Criminal Justice and Behavior, 33, 2655 .

Skeem, J.L., \& Cauffman, E. (2003). Views of the downward extension: Comparing the Youth Version of the Psychopathy Checklist with the Youth Psychopathic 
Traits Inventory. Behavioral Sciences and the Law, 21, 737-770.

Stevens, D., Charman, T., \& Blair, R.J.R. (2001). Recognition of emotion in facial expressions and vocal tones in children with psychopathic tendencies. Journal of Genetic Psychology, 162, 201.

Taylor, S. (1967). Aggressive behavior and physiological arousal as a function of provocation and the tendency to inhibit aggression. Journal of Personality, 35, 297310.

Thomaes, S., Bushman, B.J., Stegge, H., \& Olthof, T. (2008). Trumping shame by blasts of noise: Narcissism, self-esteem, shame, and aggression in early adolescence. Child Development, 79, 1792-1801.

Tremblay, R. (1998). De ontwikkeling en preventie van fysieke agressie. In W.K.W. Slot (Ed.), Van lastig tot misdadig. Houten: Bohn Stafleu Van Loghum.

Underwood, M.K., Shockner, A.E., \& Hurley, J.C. (2001). Children's responses to same- and othergender peers: An experimental investigation with 8-, 10- and 12- year-olds. Developmental Psychology, 37, 362-372.

Van Baardewijk, Y., Stegge, H., Andershed, H., Thomaes, S., Scholte, E., \& Vermeiren, R. (2008). Measuring psychopathic traits in children through self-report. The development of the Youth Psychopathic traits Inventory - Child Version. The International Journal of Law and Psychiatry, 31, 199-209.

Waschbusch, D.A., Carrey, N., Willoughby, M.T., King, S., \& Andrade, B.F. (2007). Effects of methylphenidate and behavior modification on the social and academic behavior of children with disruptive behavior disorders: The moderating role of callous/unemotional traits. Journal of Clinical Child and Adolescent Psychology, 36, 629-644.

Waschbusch, D.A., Pelham, W.E., Jennings, J.R., Greiner, A.R., Tarter, R.E., \& Moss, H.B. (2002). Reactive aggression in boys with disruptive behavior disorders: Behavior, physiology, and affect. Journal of Abnormal Child Psychology, 30, 641-656.

Zeman, J., \& Garber, J. (1996). Display rules for anger, sadness, and pain: It depends on who is watching. Child Development, 67, 957-973.

Zeman, J., \& Shipman, K. (1997). Social-contextual influences on expectancies for managing anger and sadness: The transition from middle childhood to adolescence. Developmental Psychology, 33, 917-924.

Manuscript accepted 5 August 2008 